\title{
Antiproliferative and apoptotic activities of sequence-specific histone acetyltransferase inhibitors
}

\section{AUTHOR(S):}

Yu, Zutao; Taniguchi, Junichi; Wei, Yulei; Pandian, Ganesh N.; Hashiya, Kaori; Bando, Toshikazu; Sugiyama, Hiroshi

\section{CITATION:}

Yu, Zutao ...[et al]. Antiproliferative and apoptotic activities of sequence-specific histone acetyltransferase inhibitors. European Journal of Medicinal Chemistry 2017, 138: 320-327

\section{ISSUE DATE:}

2017-09-29

URL:

http://hdl.handle.net/2433/230870

\section{RIGHT:}

(c) 2017. This manuscript version is made available under the CC-BY-NC-ND 4.0 license

http://creativecommons.org/licenses/by-nc-nd/4.0/; The full-text file will be made open to the public on 29 September 2019 in accordance with publisher's 'Terms and Conditions for Self-Archiving'.; This is not the published version. Please cite only the published version.; この論文は出版社版でありません。引用の際には出版社版をご確認ご利用ください。 


\title{
Antitumor Activity of Sequence-Specific HAT Inhibitors
}

Zutao Yu ${ }^{\mathrm{a}}$, Junichi Taniguchi ${ }^{\mathrm{a}}$, Yulei Wei ${ }^{\mathrm{a}}$, Ganesh N. Pandian ${ }^{\mathrm{b}}$, Toshikazu Bando ${ }^{\mathrm{a}^{*}}$, Hiroshi Sugiyama ${ }^{\mathrm{a}, \mathrm{b}^{*}}$

${ }^{a}$ Department of Chemistry, Graduate School of Science, Kyoto University KitashirakawaOiwakecho, Sakyo-ku, Kyoto 606-8502 (Japan)

${ }^{\mathrm{b}}$ Premier International Research Center, Institute for Integrated Cell-Material Sciences (WPIiCeMS), Kyoto University Yoshida-Ushinomiyacho, Sakyo-ku, Kyoto 606-8501 (Japan).

\begin{abstract}
In parallel to monomeric epigenetic regulators, sequence-specific epigenetic regulators represent versatile synthetic dual-function ligands that achieve regulatory control over multi-gene networks. DNA-binding domain (DBD)-HDAC inhibitors and DBD-HAT activators, which result in increased histone acetylation, have become one promising research field. However, there is no report of the gene regulatory pattern of sequence-specific epigenetic repressors. We report here the synthesis of DBD-HAT inhibitors and the evaluation of their antitumor activity in cancer cells. Among all synthesized compounds, 2 (with a medium linker length of 13-atom) exhibited the highest antitumor activity, with an $\mathrm{IC}_{50}$ of $1.8 \mu \mathrm{M}$, in A549 cells, whereas HAT inhibitor monomers showed no antiproliferative activity. In addition, we used Microarray experiment and an apoptotic assay to show that the antitumor mechanisms of $\mathbf{2}$ occurred via the regulation of p53 target genes and triggered subsequent p53-dependent apoptosis
\end{abstract}

\section{Keywords:}

Epigenetics; Sequence specificity; Polyamide; HAT inhibitor; Antitumor

\begin{abstract}
Abbreviations: HAT, histone acetyltransferase ; DBD, DNA-binding domain; HDAC, histone deacetylase; PIP, pyrrole-imidazole polyamides; DMSO, dried dimethylsulfoxide; IPA, ingenuity pathway analysis; GSEA, gene set enrichment analysis; KEGG, Kyoto encyclopedia of genes and genomes; ESI-TOF MS, electrospray ionization time-of-flight mass spectrometry, DMF, dimethylformamide; HPLC, high performance liquid chromatography; FBS, fetal bovine serum;
\end{abstract}

*Corresponding author. Department of Chemistry, Graduate School of Science, Kyoto University Kitashirakawa-Oiwakecho, Sakyo-ku, Kyoto 606-8502 (Japan)

E-mail addresses: bando@kuchem.kyoto-u.ac.jp (T. Bando), hs@kuchem.kyoto-u.ac.jp (H. Sugiyama). 


\section{Introduction}

Among epigenetic families, histone acetylation has been identified as a key histone marker that switches on gene expression. Moreover, its dysregulation might cause the development of substantial diseases [1]. Dozens of epigenetic agents, such as histone deacetylase (HDAC) inhibitors (SAHA and TSA), histone acetyltransferase ( HAT) activators (CTB and CTPB) and HAT inhibitors (C646 and anacardic acid), have been approved or are in preclinical development and show promising therapeutic efficacy [2-4]. In parallel to monomeric epigenetic regulators, sequence-specific epigenetic regulators have recently gained prominence as an emerging class of versatile synthetic dual-function ligands that achieve regulatory control over multi-gene networks

(Figure 1) [5, 6].
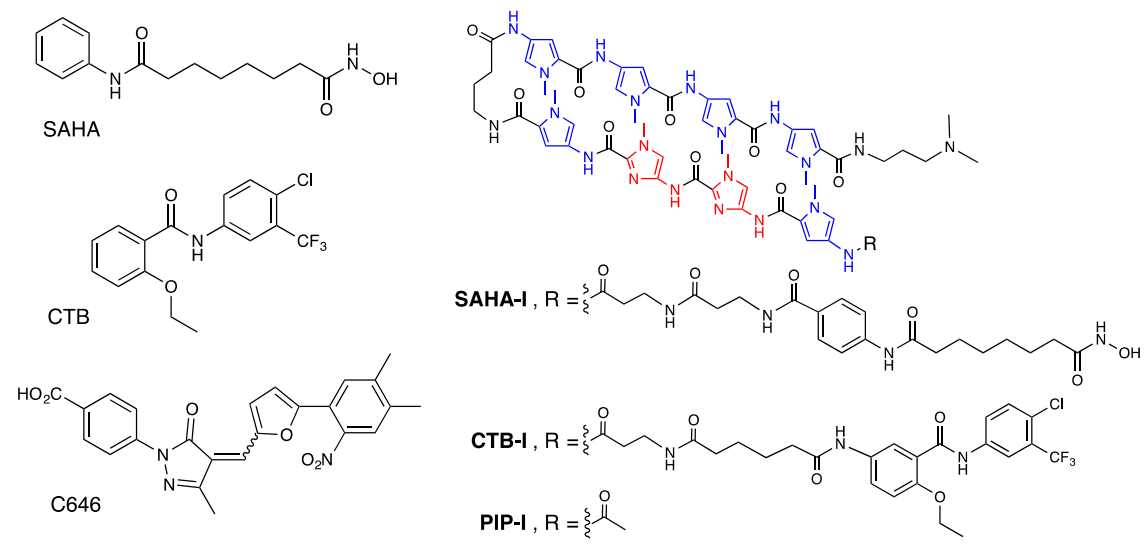

Figure 1. Chemical structures of the HDAC inhibitors SAHA and SAHA-I, HAT activators CTB and CTB-I, and HAT inhibitor C646.

Our lab has focused on sequence-specific epigenetic regulators that involve conjugation with DNA-binding domains (DBDs) and pyrrole-imidazole polyamides (PIPs) [7]. PIPs are programmable DNA minor groove binders with the ability to recognize and bind specific DNA sequences strongly (with the Py/Py pair recognizing $A / T$ or $T / A$, Py/Im recognizing $C / G$, and Im/Py recognizing G/C) [8]. By incorporating a variable 8-ring PIP moiety, a compound library of both HDAC inhibitor conjugates (SAHA-PIP) [9] and HAT activator conjugates (CTB-PIP) was constructed and showed accumulated histone acetylation, thereby being followed by downstream gene activation in living cells. Promisingly, after conjugation with SAHA, the PIP-I sequence (DNA-binding sequence, 5'-WWCCWW-3', W = A/T) exhibited the highest potential to upregulate SOX2, OCT4 and NANOG, which are responsible for iPS cell formation and maintenance (Figure 1) [10]. More interestingly, when SAHA was replaced with CTB, CTB-I showed a gene activation pattern that was similar to that of SAHA-I, although it targeted a different epigenetic regulator [11].

In contrast with SAHA and CTB, which functionally result in gene activation; however, no sequence-specific HAT inhibitor has been reported. In this work, we were interested in dualfunctional sequence-specific HAT inhibitors via C646 conjugation of PIP-I, for the development of novel cancer therapies [12]. Using our lab's platform, an in vitro HAT activity assay showed a similar HAT inhibitory pattern between sequence-specific HAT inhibitors and monomeric HAT inhibitors. In addition, a cell viability assay showed that $\mathbf{2}$ (which contains PIP-I sequence and a medium length linker) had an $\mathrm{IC}_{50}$ of $1.8 \mu \mathrm{M}$ in A549 cells. Moreover, a microarray analysis and 
an apoptotic assay revealed that upregulation of p53 target genes and apoptosis were responsible for the antitumor effect of 2 .

\section{Results and discussion}

2.1 Design and synthesis

C646, which was reported by Philip A. Cole through silica screening, is the most potent HAT inhibitor available currently. C646 inhibits p300 with a Ki value of $400 \mathrm{nM}$ in vitro and significantly downregulates histone acetylation in human lung cancer cells and melanoma cells [12]. C646 contains a carboxyl group and its amide analogs or propargylamine conjugates exhibit the same level of HAT inhibitory activity, which implies that PIP conjugation at the carboxyl site is a good choice, while maintaining HAT inhibitory activity [13].

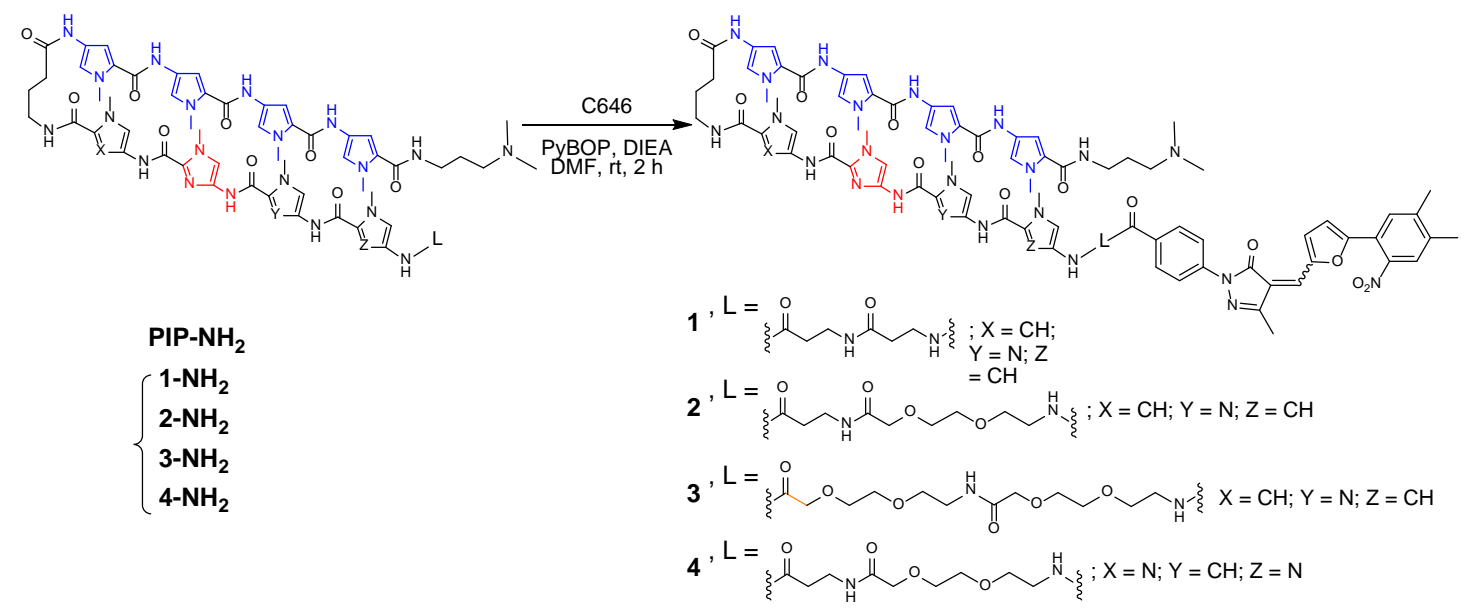

Scheme 1. Structural design of PIP conjugates of the HAT inhibitor C646 (C646-PIP).

Inspired by the 8-ring PIP-I, we moved forward to PIP-I conjugation with the HAT inhibitor C646 (C646-I) [11].The linker region between the functional group and PIP might affect its binding affinity and functional effect. Our group reported six kinds of linkers of SAHA-PIP and revealed that a linker length of 12-atom yielded maximum expression of OCT3/4[14]. In this work, after taking linker length and chain flexibility into consideration, we designed C646-PIP-I conjugates with three types of linkers, i.e., a shorter linker (8-atom, 1), a moderate linker (13atom, 2) and a longer linker (18-atom, 3) (Scheme 1). Concomitantly, an alternative PIP sequence ligated with C646 (4) was also designed, to investigate the PIP sequence/activity relationship. C646-PIP synthesis started from pyrrole-oxime resin [15]. Using an 11-step Fmoc-protected solidphase synthesis, four conjugates were synthesized and cleaved by $N, N$-dimethylamine. After purification using a reverse-phase flash column, our target compounds were synthesized by combining the terminal amino group of the PIP chain with commercially available C646, which contains a carboxyl group, with the help of the coupling agent PyBOP. The compounds were then purified in high yield.

\subsection{In vitro HAT activity assay}

After conjugation with PIP, functional moieties, such as SAHA, CTB, and alkylating agents, still harbor their functional activity toward the primary targets, with only a slight loss of activity [16]. 
Therefore, it is mandatory that the conjugation of PIP-I with C646 does not diminish the histone acetylation inhibitory activity. We first evaluated the HAT activity of all synthesized C646-PIP conjugates using a commercially available HAT activity kit. We used p300 as the HAT enzyme, as C646 showed high selectivity to p300 compared with a panel of similar functional enzymes, such as PCAF, GCN5, AANAT, Sas, Moz, and Rtt109 [12]. The HAT inhibitory activity was assessed using fluorescence absorption on a microreader using the H3 peptide and Ac-CoA as substrates.

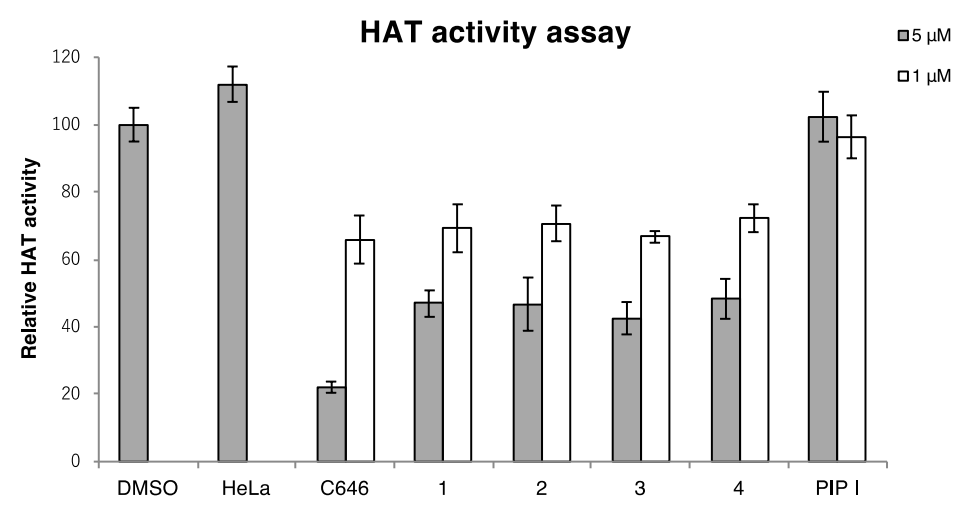

Figure 2. HAT inhibitory activity assay. The enzymatic activity of HAT was tested in the presence of C646, 1, 2, 3, 4, and PIP-I. Each effector was individually administered at two concentrations ( 1 and $5 \mu \mathrm{M}$ ) to the p300 enzyme using a HeLa cell nuclear extract as a positive control and the 0.5\% DMSO group as a control group (100\%). $P<$ 0.05 .

Our results showed an $\mathrm{IC}_{50}$ of $2.4 \mu \mathrm{M}$ for C646, which is consistent with that reported previously. As expectedly, the PIP-I sequence without C646 did not possess HAT inhibitory activity. Concomitantly, all C646-PIP derivatives, regardless of linker region and PIP sequence, maintained HAT inhibitory activity, with IC 50 values around 3.9-4.2 $\mu \mathrm{M}$, which proved that C646-PIP preserved p300 inhibitory activity and the changes in PIP sequence had no obvious deleterious effects on IC ${ }_{50}$. In addition, the inhibitory activity of C646-PIP was slightly decreased compared with the C646 monomer, which might be explained by the fact that the PIP moiety constrains C646 binding to HAT, to a certain extent.

\subsection{Antitumor activity assay}

HAT inhibitors were studied in cancer cell lines in previous reports [3, 17]. After a 10-day treatment, C646 exhibited an $\mathrm{IC}_{50}$ of 10.0, 6.0, and $6.3 \mu \mathrm{M}$ in A549, H157, and H460 cells, respectively, as assessed by a clonogenic survival assay based on a published article [18]. Under ionizing radiation therapy, C646 radiosensitized lung cancer cells by enhancing the mitotic catastrophe. However, those authors could only observe a limited dose ratio enhancement of 1.21.4 fold, which implies that an alternative molecular design should be introduced. 


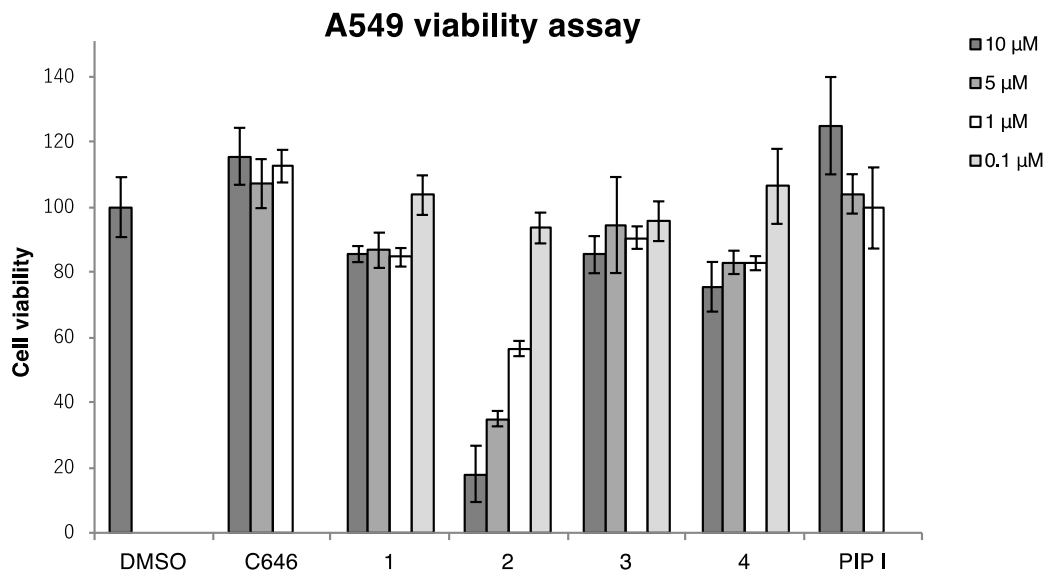

Figure 3. Cell viability assay in the A549 cell line using the WST-8 method. A549 cells were grown in $10 \%$ FBS/DMEM medium for $24 \mathrm{~h}$. Subsequently, the medium was replenished with varying concentrations of C646PIP conjugates $(0.1,1,5$, and $10 \mu \mathrm{M})$ for $96 \mathrm{~h}$. The cell viability of A549 cells was measured using the WST-8 method. Each bar represents the mean \pm SD from three wells. $P<0.05$.

Here, we studied the antitumor activity of C646-PIP using a cell viability assay in A549 cells [19]. As expectedly, A549 cell viability was almost not affected by PIP-I and C646, even at the concentration of $10 \mu \mathrm{M}$, after $96 \mathrm{~h}$ of treatment (Figure 3). Treatment with C646-PIP conjugates led to cell inhibition, , but the extent of activity varied considerably among conjugates with different linker lengths and PIP sequences.

Regarding the shared PIP-I sequence, 2 (moderate linker with a 13-atom distance) exhibited the highest antitumor activity, with an $\mathrm{IC}_{50}$ of $1.8 \mu \mathrm{M}$, in a dose-dependent manner. This implies that the length of the linker played a pivotal role regarding its cellular effect, which was different from the simplified HAT inhibitory activity in vitro. If the linker length was too short (1), C646 was not sufficiently free to bind to the active pocket of p300 while PIP bound to DNA. In contrast, a linker that was too long (3) drove C646 out of the localized region of PIP binding, without sequencespecificity. 2 and 4 had the same linker length (13-atom distance), but different PIP sequences. However, $\mathbf{4}$ showed only a slight antitumor activity in A549 cells, which implies that the PIP-I sequence is necessary for antitumor activity.

We also tested 2 and 4 in SW620 cells, which contained mutant p53 (A549 cells contained wildtype p53) (Supplementary Data S3). Our results showed that 2 had less activity in SW620 cells (IC $\left.\mathrm{I}_{50}, 7.5 \mu \mathrm{M}\right)$ compared with that observed in A549 cells (IC $\left.\mathrm{I}_{50}, 1.85 \mu \mathrm{M}\right)$.

\subsection{Microarray analysis}

Microarray analysis has been used widely to identify underlying regulatory gene patterns [20]. In this work, whole-genome transcriptional profiling of the A549 cell line was performed using microarray analysis, according to the manufacturer's protocol [21]. $2(2 \mu \mathrm{M})$ and $4(2 \mu \mathrm{M})$ were added respectively, for 48 h. 4 did not exhibit a specific gene regulatory pattern, which was consistent with its low antitumor activity. Regarding treatment with 2, among the more than 50,000 transcripts identified, 310 target genes showed 1.5-fold changes in expression levels $(P<$ 0.05), with upregulation observed for 170 transcripts and downregulation detected for 140 
transcripts. Genes detail information of microarray data up- and downregulated by treatment with 2 with levels $>1$.8-fold and $<-1.8$-fold changes $(p<0.05)$ by Affymetrix gene expression console software (Table 1).

Table 1 Genes detail information of microarray data up- and downregulated by treatment with 2 . Genes with $>1.8$ fold and $<-1.8$-fold changes $(P<0.05)$. Uncharacterized transcripts were excluded from this table. Gene symbols in red color and green color are upregulated and downregulated p53 downstream targets, respectively.

\begin{tabular}{|cc|cc|}
\hline Gene Symbol & Fold Change & Gene Symbol & Fold Change \\
\hline SPATA18 & 2.98 & TP53INP1 & 1.85 \\
EDA2R & 2.53 & CD70 & 1.83 \\
ABCA12 & 2.42 & FAS & 1.83 \\
BTG2 & 2.35 & GDF15 & 1.81 \\
MIR3189 & 2.32 & GAS6-AS1 & 1.81 \\
CDKN1A & 2.28 & ANKRD1 & 1.81 \\
SULF2 & 2.13 & DDB2 & 1.80 \\
WDR63 & 2.03 & NEFL & 1.80 \\
FDXR & 2.00 & SNORA9 & -1.81 \\
MDM2 & 1.97 & ALDH1L2 & -1.86 \\
UIMC1 & 1.94 & CARS & -1.90 \\
MIR4713 & 1.94 & ASNS & -2.01 \\
SESN1 & 1.91 & TAS2R30 & -2.01 \\
SCARNA7 & 1.89 & STC2 & -2.34 \\
MIR3685 & 1.89 & ULBP1 & -2.34 \\
CYFIP2 & 1.88 & GUSBP3 & -2.63 \\
POLH & 1.88 & CHAC1 & -3.64 \\
\hline
\end{tabular}

We performed an Ingenuity Pathway Analysis (IPA) of the differentially expressed genes, to gain a more precise global understanding of the underlying biological processes (Figure 4a) [22]. Interestingly, while 4 did not show potent and specific gene pattern regulations, treatment with 2 led to a strong enrichment of p53 target genes, such as SPATA18 (2.98 fold), BTG2 (2.35 fold), FDXR (2.00 fold), and MDM2 (1.97 fold), among the top regulated transcripts. We then performed a Gene Set Enrichment Analysis (GSEA) of the significantly differentially regulated genes using the published gene expression profiles of p53 targets with gene sets of the Kyoto Encyclopedia of Genes and Genomes (KEGG) (Supplementary Data S4) [23]. Consistent with the IPA analysis, GSEA demonstrated that the p53 signaling pathway was predominantly enriched among all 185 gene sets identified, with an enrichment score of 0.67 and a $P$ value $<0.001$ (Figure $4 b)$.
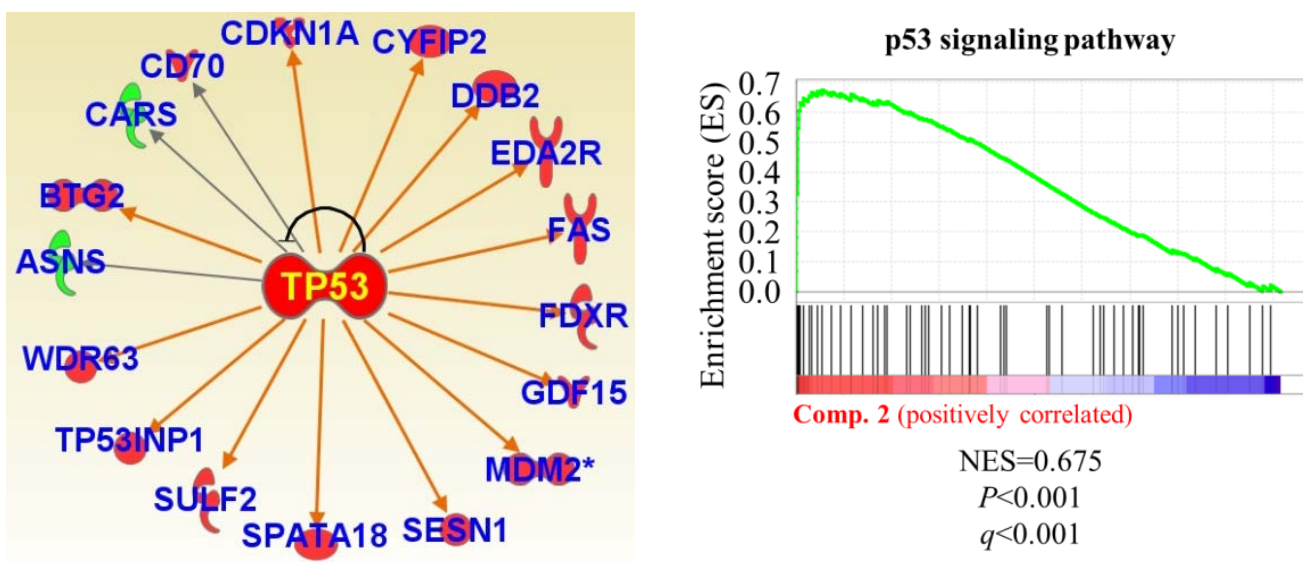

Figure 4 a) Significantly enriched target genes annotation in p53 by IPA. Targeting genes depicting the effect of 2 (compared with DMSO) the expression pattern of p53 pathway target genes in the technical duplicates of whole transcriptome analysis $(P<0.05)$ regulated at least 1.8 -fold. b) A Gene Set Enrichment Analysis (GSEA) was performed to assess whether genes that were differentially repressed by $\mathbf{2}$ were significantly associated with p53 
direct effectors expression profiles of KEGG gene sets and gene symbols (GSEA database c2.cp.kegg.v5.2.symbols.gmt). The enrichment score clearly showed that the genes at the top of the ranked list were overrepresented in the reference gene set. $P<0.001$ and $q<0.001$.

A549 cells contain wild-type p53. Previous reports demonstrated that wild-type p53 plays a significant role in tumor inhibition. Stabilizing p53 and selectively activating p53 targets in p53 wild-type cells resulted in a pronounced antiproliferative effect by inducing cell-cycle arrest and apoptosis[24]. One issue should be clarified here. As SAHA-I and CTB-I activated SOX2, OCT4, and NANOG in somatic human cells, while showing no antiproliferative activity, treatment with 2 showed slight decreases of pluripotent genes after detail inspection of microarray data. Previous report demonstrated that downregulation of p53 pathway is required for efficient iPS cell reprogramming and maintenance[25]. To the contrast, the inhibition of pluripotent genes might result in p53 pathway activation based on the microarray data. Furthermore, 2 showed weak antitumor activity in p53-mutant SW620 cells. Therefore, these results combined with the cell viability assay and Microarray experiment discussed above led us to conclude that the antitumor activity caused by 2 in A549 cells was mainly attributable to the activation of p53 targeting genes.

\subsection{Apoptotic assay in the A549 cell line}

Among the many roles of tumor suppressor p53, the role of p53-dependent apoptosis in pathological conditions was identified a long time ago, especially in cancer[24]. The microarray results led us to presume that p53-denpendent apoptosis might be the antitumor mechanism underlying the effects observed for 2.

To confirm this hypothesis, cellular apoptosis was investigated via Annexin V-FITC assay, together with living cells and dead cells staining [26]. A549 cells were treated with $\mathbf{2}$ and $\mathbf{4}$ for 48 h. Subsequently, apoptotic, necrotic, and healthy cells were stained with three different fluorophores (FITC-annexin V, ethidium homodimer III, and Hoechst 33342) (Figure 5).

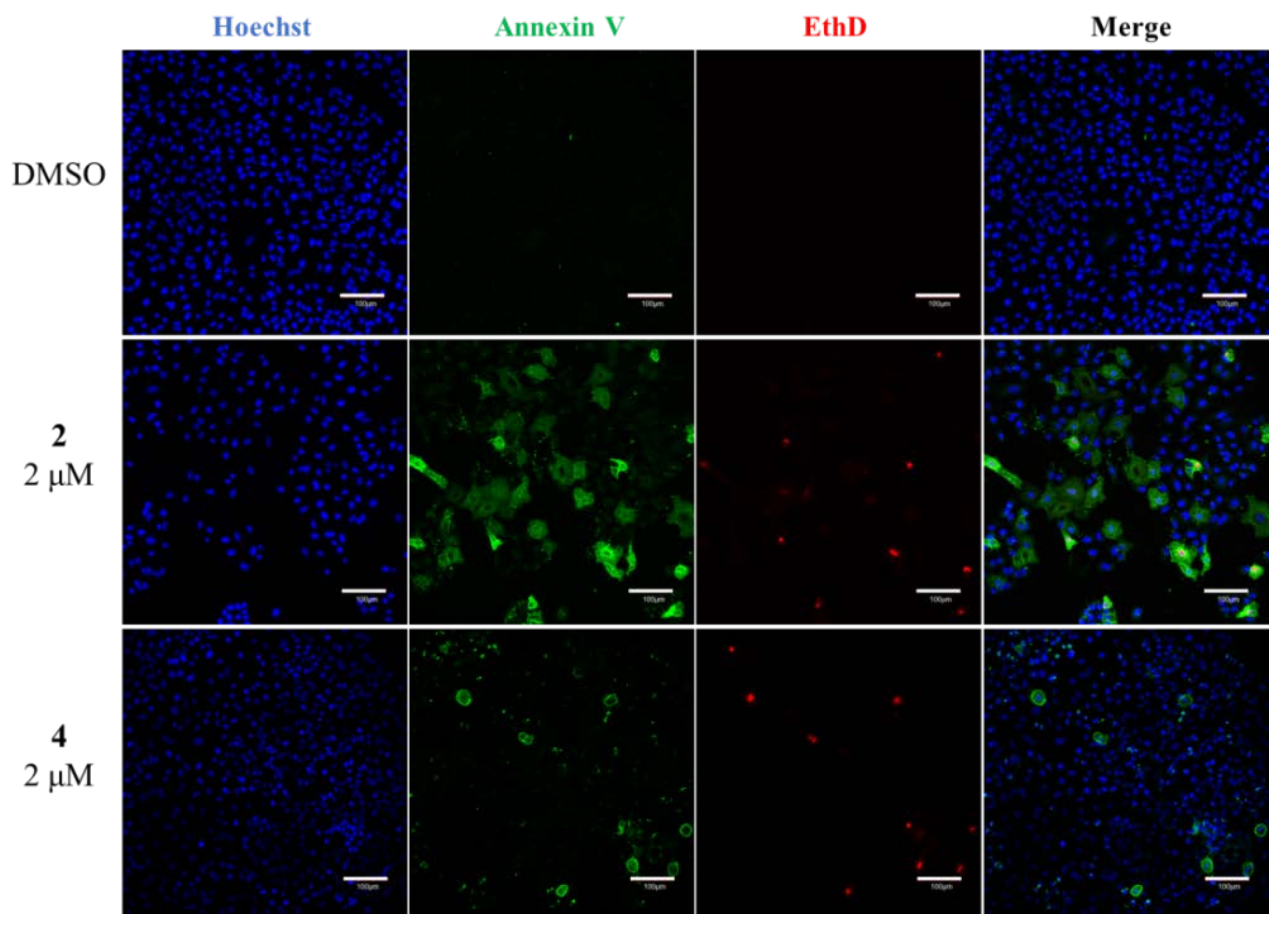


Figure 5. Effect of $\mathbf{2}$ and $\mathbf{4}$ on cellular apoptosis and necrotic activity. Representative images of apoptosis detection using fluorescence imaging. A549 cells were treated with DMSO, 2, and 4 at $2 \mu \mathrm{M}$ for $48 \mathrm{~s}$. A confocal image showed Hoechst 33342 staining, FITC-annexin V staining, ethidium homodimer III staining, and an overlay of the images. (scale bars represent $100 \mu \mathrm{m}$ ).

In accordance with the $\mathrm{IC}_{50}$ of $\mathbf{2}, 2 \mu \mathrm{M} \mathbf{2}$ and $\mathbf{4}$ were applied to observe the process of cell death. In the control experiment (0.1\% DMSO), apoptotic/dead cells were difficult to detect. Conversely, cultures treated with 2 showed more abundant apoptotic cells and an obvious subset of dead cells, which was consistent with the results of the cell viability assay described above. For $\mathbf{4}$, most of the cells were in a healthy condition, and only a few necrotic cells and apoptotic cells were detected. As wild-type p53 plays a major role in A549 cell apoptosis, these results suggested that 2 activated p53 downstream targets and induced cell apoptosis, leading to programmed cell death.

\section{Conclusions}

In addition to DNA mutation, heritable phenotypes, such as the inactivation of tumor suppressor genes, can also be acquired by epigenetic modifications, including DNA methylation and histone modifications [27]. Inactivation of tumor suppressors and their downstream pathways, such as the p53 pathway, or activation of proto-oncogenes and their correspondent pathways, such as the RAS pathway, have been studied widely and play pivotal roles in tumor initiation and development. Wild-type p53 plays a significant role in tumor inhibition. Stabilizing p53 and selectively activating the p53 pathway in p53 wild-type cells resulted in a pronounced antiproliferative effect via the induction of cell-cycle arrest and apoptosis [28]. In contrast, mutations in the p53 tumor suppressor gene are associated clinically with cancer stem cell progression and metastasis[29].

In this study, we reported, for the first time, conjugates of DNA-binding domain and HAT inhibitors and evaluated their antitumor activity in A549 and SW620 cells. Among the C646-PIP derivatives identified, 2 (with a medium linker length of 13-atom) showed a potent antitumor activity with an $\mathrm{IC}_{50}$ of $1.8 \mu \mathrm{m}$ in A549 cells. Moreover, with the help of Microarray analysis and an apoptosis assay, we demonstrated that the antitumor mechanism of $\mathbf{2}$ occurred via the activation of p53 target genes and triggered subsequent p53-dependent apoptosis.

\section{Experimental section}

\subsection{General methods}

Reagents and solvents were purchased from standard suppliers and used without further purification. HAT inhibitor C646 was purchased from Sigma-aldrich (SML0002-25 mg). HPLC analysis were performed with a JASCO PU-2080 plus HPLC pump, a JASCO 807-IT HPLC UV/Vis detector, and a Chemcobond 5-ODS-H reversed-phase column $(4.6 \times 150 \mathrm{~mm})$ in $0.1 \%$ TFA in water using acetonitrile as the eluent at a flow rate of $1.0 \mathrm{~mL} \mathrm{~min}^{-1}$ under detection at 254 $\mathrm{nm}$. Electrospray ionization Time-of-flight mass spectrometry (ESI-TOF MS) was performed on a Bio-TOF II (Bruker Daltonics) mass spectrometer by using positive ionization mode. Machineassisted PIP syntheses were performed on a PSSM-8 (Shimadzu) system with computer-assisted operation on a $20 \mu \mathrm{mol}$ scale using Fmoc chemistry.

\subsection{HAT inhibitor-PIP synthesis}

Machine-assisted automatic solid-phase synthesis of hairpin-type PIP was carried out with the 
use of a continuous-flow peptide synthesizer (PSSM-8, Shimadzu, Kyoto, Japan) at $0.1 \mathrm{mmol}$ scale (100 mg of Fmoc oxime resin, 0.50 meq/g, Peptide Institute, Osaka, Japan) [15]. In a stepwise reaction, Fmoc-Py-COOH, Fmoc-Im-COOH, Fmoc-Py-Im-COOH, Fmoc- $\beta$-alanine$\mathrm{COOH}$, 4-(Fmoc-amino) butyric acid and Fmoc-4,7-dioxanonanoic acid were coupled sequentially. Automatic solid-phase synthesis was started by washing with dimethylformamide (DMF); coupling with a monomer for $60 \mathrm{~min}$ in an environment of 1[bis(dimethylamino)methylene]- 5-chlorobenzotriazolium 3-oxide hexafluorophosphate (HCTU) and diisopropylethylamine (4 eq. each); removing the Fmoc group using 20\% piperidine/DMF. We then isolated PIP after cleavage step (1 ml $N, N$-Dimethylpropylamine) for compound 1-4.

Through 11-step solid phase synthesis and reverse-phase flash column, four PIPs were successfully synthesized. Then, our target compounds were synthesized and purified in high yield by conjugating commercially available C646 with $\mathbf{1}-\mathbf{N H}_{2}, \mathbf{2}-\mathbf{N H}_{2}, \mathbf{3}-\mathbf{N H}_{\mathbf{2}}$ and $\mathbf{4 - \mathbf { N H } _ { 2 }}$ respectively with the help of coupling agent PyBOP. To purify the PIP conjugates, high performance liquid chromatography (HPLC) was performed with use of a PU-980 HPLC pump, UV-975 HPLC UV/VIS detector (Jasco, Easton, MD), and Chemcobound 5-ODS-H column (Chemco Scientific, Osaka, Japan).

PIP-I was obtained as a white powder. MS (ESI-TOF): $m / z$ calcd for $\mathrm{C}_{57} \mathrm{H}_{71} \mathrm{~N}_{21} \mathrm{O}_{10}{ }^{2+}[M+2 \mathrm{H}]^{2+}$ : 604.7841; found: 6047302; HPLC: $t_{\mathrm{R}}=16.09 \mathrm{~min}(0.1 \% \mathrm{TFA} / \mathrm{MeCN}$, linear gradient $0-100 \%, 0$ $40 \mathrm{~min})$.

1-NH $\mathrm{NH}_{2}$ was obtained as a white powder. MS (ESI-TOF): $\mathrm{m} / \mathrm{z}$ calcd for $\mathrm{C}_{61} \mathrm{H}_{77} \mathrm{~N}_{23} \mathrm{O}_{11}{ }^{2+}[M+2 \mathrm{H}]^{2+}$ : 654.8159; found: 654.6877; HPLC: $t_{\mathrm{R}}=10.06 \mathrm{~min}(0.1 \% \mathrm{TFA} / \mathrm{MeCN}$, linear gradient $0-100 \%, 0$ $20 \mathrm{~min})$.

2- $\mathrm{NH}_{2}$ was obtained as a white powder. MS (ESI-TOF): $\mathrm{m} / \mathrm{z}$ calcd for $\mathrm{C}_{64} \mathrm{H}_{85} \mathrm{~N}_{23} \mathrm{O}_{13}{ }^{2+}[M+2 \mathrm{H}]^{2+}$ : 691.8343; found: 691.6911; HPLC: $t_{\mathrm{R}}=10.11 \mathrm{~min}(0.1 \% \mathrm{TFA} / \mathrm{MeCN}$, linear gradient $0-100 \%, 0$ $20 \mathrm{~min})$.

3-NH $\mathrm{NH}_{2}$ was obtained as a white powder. MS (ESI-TOF): $\mathrm{m} / \mathrm{z}$ calcd for $\mathrm{C}_{67} \mathrm{H}_{91} \mathrm{~N}_{23} \mathrm{O}_{15}{ }^{2+}[M+2 \mathrm{H}]^{2+}$ : 728.8527; found: 728.7889; HPLC: $t_{\mathrm{R}}=10.18 \mathrm{~min}(0.1 \% \mathrm{TFA} / \mathrm{MeCN}$, linear gradient $0-100 \%, 0$ $20 \mathrm{~min})$.

4-NH $\mathrm{NH}_{2}$ was obtained as a white powder. MS (ESI-TOF): $\mathrm{m} / \mathrm{z}$ calcd for $\mathrm{C}_{63} \mathrm{H}_{84} \mathrm{~N}_{24} \mathrm{O}_{13}{ }^{2+}[M+2 \mathrm{H}]^{2+}$ : 692.3320; found: 692.3352; HPLC: $t_{\mathrm{R}}=9.692 \mathrm{~min}(0.1 \% \mathrm{TFA} / \mathrm{MeCN}$, linear gradient $0-100 \%, 0$ $20 \mathrm{~min})$.

1 was obtained as a red powder. MS (ESI-TOF): $\mathrm{m} / \mathrm{z}$ calcd for $\mathrm{C}_{85} \mathrm{H}_{96} \mathrm{~N}_{26} \mathrm{O}_{16}{ }^{2+}[M+2 \mathrm{H}]^{2+}$ : 868.3744; found: 868.2229; HPLC: $t_{\mathrm{R}}=14.05 \mathrm{~min}(0.1 \% \mathrm{TFA} / \mathrm{MeCN}$, linear gradient $0-100 \%, 0$ $20 \mathrm{~min})$.

2 was obtained as a red powder. MS (ESI-TOF): $\mathrm{m} / \mathrm{z}$ calcd for $\mathrm{C}_{88} \mathrm{H}_{102} \mathrm{~N}_{26} \mathrm{O}_{18}{ }^{2+}[\mathrm{M}+2 \mathrm{H}]^{2+}$ : 905.3927; found: 905.3164; HPLC: $t_{\mathrm{R}}=14.10 \mathrm{~min}(0.1 \% \mathrm{TFA} / \mathrm{MeCN}$, linear gradient $0-100 \%, 0$ $20 \mathrm{~min})$.

3 was obtained as a red powder. MS (ESI-TOF): $m / z$ calcd for $\mathrm{C}_{91} \mathrm{H}_{108} \mathrm{~N}_{26} \mathrm{O}_{20}{ }^{2+}[M+2 \mathrm{H}]^{2+}$ : 942.4111; found: 942.4408; HPLC: $t_{\mathrm{R}}=14.19 \mathrm{~min}(0.1 \% \mathrm{TFA} / \mathrm{MeCN}$, linear gradient $0-100 \%, 0$ $20 \mathrm{~min})$.

4 was obtained as a red powder. MS (ESI-TOF): $m / z$ calcd for $\mathrm{C}_{87} \mathrm{H}_{101} \mathrm{~N}_{27} \mathrm{O}_{18}{ }^{2+}[M+2 \mathrm{H}]^{2+}$ : 905.8904; found: 906.0553 ; HPLC: $t_{\mathrm{R}}=13.83 \mathrm{~min}(0.1 \% \mathrm{TFA} / \mathrm{MeCN}$, linear gradient $0-100 \%$, 0 $20 \mathrm{~min}$ ). 
Concentration determination: $410 \mathrm{~nm}$. C646-PIP concentrations were calibrated by comparing UV absorbance at $410 \mathrm{~nm}$ to C646.

\subsection{HAT activity assay in vitro}

HAT activity assays were determined using a commercial available kit (Biovision Biotechnology) according to the manufacturer's instruction [11]. BioVision's HAT Activity Assay Kit utilizes Acetyl CoA and H3 histone peptide as substrates, and recombinant p300 core domain as the enzyme. In this assay, HAT enzyme catalyzes the transfer of acetyl groups from Acetyl-CoA to the histone peptide, thereby generating two products - acetylated peptide and CoA-SH. The CoA-SH reacts with the developer to generate a product that is detected fluorometrically at Ex/Em $=535 / 587 \mathrm{~nm}$.

\subsection{Cell culture}

The base medium for A549 cell line is ATCC-formulated DMEM medium. To make the complete growth medium, we added the following components to the base medium for A549 cells: fetal bovine serum (Sigma FBS) to a final concentration of $10 \%$ and L-glutamin to a final percentage of $2 \mathrm{mM}$. SW620 cell line is supplemented with 1x penicillin/streptomycin. To make the complete growth medium, we added the following components to the base medium: FBS to a final concentration of $10 \%$ and penicillin/streptomycin to a final concentration of $1 \%$.

\subsection{Cell proliferation assay}

A549 and SW620 cells were seeded on 96-well microplates $\left(5 \times 10^{3}\right.$ cells/well) in above mentioned media for $24 \mathrm{~h}$ at $37^{\circ} \mathrm{C}$ in $5 \% \mathrm{CO}_{2}$. Then media was replenished with varying concentrations of conjugates C646-PIP for 96 h. Count Reagent SF (Nacalai Tesque) was added to each well to evaluate the cell proliferation. The absorbance of each well was measured at $450 \mathrm{~nm}$ by SpectraMax M2 (Molecular devices) microplate reader.

\subsection{Microarray analysis and data processing}

A549 cells were plated in 6-well plates at $2 \times 10^{5}$ cells/well and were treated for $48 \mathrm{hr}$ with DMSO (0.01\% control) and $1 \mu \mathrm{M}$ concentration of PIP1, with technical duplicates in each condition respectively. Total RNA was prepared and the integrity of the RNA was checked using the Agilent 2100 Bioanalyzer (Agilent Technologies). One hundred nanograms of total RNA quantified by Nanodrop ND1000 v. 3.5.2 (Thermo Scientific) was labeled using a GeneChip WT PLUS Reagent kit (Affymetrix) and was hybridized to Human Gene 2.1 ST Array Strip (Affymetrix) for $20 \pm 1 \mathrm{hr}$ at $48^{\circ} \mathrm{C}$. The hybridized arrays were washed, stained, and imaged on a GeneAtlas Personal Microarray System (Affymetrix). The hybridized probe set values were normalized using Affymetrix gene expression console software. Significant differentially expressed genes between the different conditions were analyzed using t test statistics $(p<0.05)$. Microarray data reported here were deposited in the Gene Expression Omnibus database under the accession number (currently unavailable).

Gene set enrichment analysis (GSEA) was conducted to detect statistically significant 2 targeted genes associated with a gene set p53-regulated genes. Data were further analyzed by IPA (Ingenuity Systems; http://www.ingenuity.com) [23]. The IPA functional analysis was 
conducted to identify the significant biological functions associated with the microarray data set. Genes from the data sets that were regulated by $\geqslant 1.8$-fold cutoff at $p<0.05$ were considered for the analysis. The $p$ value was calculated using right-tailed Fisher's exact test that defines the degree of association of the data set to the assigned biological function.

\subsection{Apoptosis Detection assay}

The apoptosis detection assay was performed using an Apoptotic, Necrotic, and Healthy Cells Detection Kit (Promokine) according to manufacturer's instructions [26]. A549 cells were cultured in 8-well chamber slides at a density of $2 \times 10^{4}$ cells/well and treated with $2 \mu \mathrm{M}$ PIP for $48 \mathrm{hr}$. Cells were washd with a binding buffer and stained with FITC-Annexin V, Ethidium Homodimer III, and Hoechst 33342; then they were subjected to fluorescence microscopy analysis (SpectraMax M2, Molecular Devices).

\subsection{Statistical analysis}

Results for continuous variables were presented as the mean \pm standard error. Two-group differences in continuous variables were assessed by the unpaired T-test. $P$-values are twotailed with confidence intervals of $95 \%$. Statistical analysis was performed by comparing treated samples with untreated controls..

\section{Acknowledgments}

This work was supported by JSPS KAKENHI (24225005), "Basic Science and Platform Technology Program for Innovative Biological Medicine" and "JSPS-NSF International Collaborations in Chemistry (ICC)” to H.S. and Grant No. z4310155-to T.B. We also thank China Scholarship Council (CSC) support Z. Y., Japanese Government (MONBUKAGAKUSHO: MEXT) Scholarship support Y. W. and JSPS scholarship support J. T.

\section{Appendix A. Supplementary data}

Supplementary data related to this article can be found at http://dx.doi.org/.

\section{References}

[1] A.P. Feinberg, M.A. Koldobskiy, A. Gondor, Epigenetic modulators, modifiers and mediators in cancer aetiology and progression, Nat. Rev. Genet., 17 (2016) 284-299.

[2] M. Mottamal, S.L. Zheng, T.L. Huang, G.D. Wang, Histone Deacetylase Inhibitors in Clinical Studies as Templates for New Anticancer Agents, Molecules, 20 (2015) 3898-3941.

[3] S. Castellano, C. Milite, A. Feoli, M. Viviano, A. Mai, E. Novellino, A. Tosco, G. Sbardella, Identification of Structural Features of 2-Alkylidene-1,3-Dicarbonyl Derivatives that Induce Inhibition and/or Activation of Histone Acetyltransferases KAT3B/p300 and KAT2B/PCAF, ChemMedChem, 10 (2015) 144-157.

[4] K.C. Ravindra, B.R. Selvi, M. Arif, B.A. Reddy, G.R. Thanuja, S. Agrawal, S.K. Pradhan, N. Nagashayana, D. Dasgupta, T.K. Kundu, Inhibition of lysine acetyltransferase KAT3B/p300 activity by a naturally occurring hydroxynaphthoquinone, plumbagin, J. Biol. Chem., 284 (2009) 24453-24464.

[5] G.N. Pandian, J. Taniguchi, S. Junetha, S. Sato, L. Han, A. Saha, C. AnandhaKumar, T. Bando, H. Nagase, T. Vaijayanthi, R.D. Taylor, H. Sugiyama, Distinct DNA-based epigenetic switches trigger transcriptional activation of silent genes in human dermal fibroblasts, Sci Rep, 4 (2014) e3843. 
[6] L. Han, G.N. Pandian, S. Junetha, S. Sato, C. Anandhakumar, J. Taniguchi, A. Saha, T. Bando, H. Nagase, H. Sugiyama, A synthetic small molecule for targeted transcriptional activation of germ cell genes in a human somatic cell, Angew Chem Int Ed Engl, 52 (2013) 13410-13413.

[7] G.N. Pandian, K. Shinohara, A. Ohtsuki, Y. Nakano, M. Masafumi, T. Bando, H. Nagase, Y. Yamada, A. Watanabe, N. Terada, S. Sato, H. Morinaga, H. Sugiyama, Synthetic small molecules for epigenetic activation of pluripotency genes in mouse embryonic fibroblasts, Chembiochem, 12 (2011) 2822-2828.

[8] S. White, J.W. Szewczyk, J.M. Turner, E.E. Baird, P.B. Dervan, Recognition of the four WatsonCrick base pairs in the DNA minor groove by synthetic ligands, Nature, 391 (1998) 468-471.

[9] G.N. Pandian, Y. Nakano, S. Sato, H. Morinaga, T. Bando, H. Nagase, H. Sugiyama, A synthetic small molecule for rapid induction of multiple pluripotency genes in mouse embryonic fibroblasts, Sci Rep, 2 (2012) e544.

[10] G.N. Pandian, S. Sato, C. Anandhakumar, J. Taniguchi, K. Takashima, J. Syed, L. Han, A. Saha, T. Bando, H. Nagase, H. Sugiyama, Identification of a small molecule that turns ON the pluripotency gene circuitry in human fibroblasts, ACS Chem Biol, 9 (2014) 2729-2736.

[11] L. Han, G.N. Pandian, A. Chandran, S. Sato, J. Taniguchi, G. Kashiwazaki, Y. Sawatani, K. Hashiya, T. Bando, Y. Xu, X. Qian, H. Sugiyama, A Synthetic DNA-Binding Domain Guides Distinct Chromatin-Modifying Small Molecules to Activate an Identical Gene Network, Angew Chem Int Ed Engl, 54 (2015) 8700-8703.

[12] E.M. Bowers, G. Yan, C. Mukherjee, A. Orry, L. Wang, M.A. Holbert, N.T. Crump, C.A. Hazzalin, G. Liszczak, H. Yuan, C. Larocca, S.A. Saldanha, R. Abagyan, Y. Sun, D.J. Meyers, R. Marmorstein, L.C. Mahadevan, R.M. Alani, P.A. Cole, Virtual Ligand Screening of the p300/CBP Histone Acetyltransferase: Identification of a Selective Small Molecule Inhibitor, Chem. Biol., 17 (2010) 471482.

[13] J.H. Shrimp, A.W. Sorum, J.M. Garlick, L. Guasch, M.C. Nicklaus, J.L. Meier, Characterizing the Covalent Targets of a Small Molecule Inhibitor of the Lysine Acetyltransferase P300, ACS Med. Chem. Lett., 7 (2016) 151-155.

[14] G.N. Pandian, A. Ohtsuki, T. Bando, S. Sato, K. Hashiya, H. Sugiyama, Development of programmable small DNA-binding molecules with epigenetic activity for induction of core pluripotency genes, Bioorg Med Chem, 20 (2012) 2656-2660.

[15] H. Morinaga, T. Bando, T. Takagaki, M. Yamamoto, K. Hashiya, H. Sugiyama, Cysteine cyclic pyrrole-imidazole polyamide for sequence-specific recognition in the DNA minor groove, J Am Chem Soc, 133 (2011) 18924-18930.

[16] C. Guo, S. Asamitsu, G. Kashiwazaki, S. Sato, T. Bando, H. Sugiyama, DNA Interstrand Crosslinks by H-pin Polyamide (S)-seco-CBI Conjugates, ChemBioChem, 18 (2017) 166-170.

[17] X.-n. Gao, J. Lin, Q.-y. Ning, L. Gao, Y.-s. Yao, J.-h. Zhou, Y.-h. Li, L.-l. Wang, L. Yu, A Histone Acetyltransferase p300 Inhibitor C646 Induces Cell Cycle Arrest and Apoptosis Selectively in AML1ETO-Positive AML Cells, PloS one, 8 (2013) e55481.

[18] T. Oike, M. Komachi, H. Ogiwara, N. Amornwichet, Y. Saitoh, K. Torikai, N. Kubo, T. Nakano, T. Kohno, C646, a selective small molecule inhibitor of histone acetyltransferase p300, radiosensitizes lung cancer cells by enhancing mitotic catastrophe, Radiother. Oncol., 111 (2014) 222-227.

[19] G. Kashiwazaki, T. Bando, T. Yoshidome, S. Masui, T. Takagaki, K. Hashiya, G.N. Pandian, J. Yasuoka, K. Akiyoshi, H. Sugiyama, Synthesis and Biological Properties of Highly Sequence-SpecificAlkylatingN-Methylpyrrole-N-Methylimidazole Polyamide Conjugates, Journal of Medicinal 
Chemistry, 55 (2012) 2057-2066.

[20] F. Yang, N.G. Nickols, B.C. Li, G.K. Marinov, J.W. Said, P.B. Dervan, Antitumor activity of a pyrrole-imidazole polyamide, Proc Natl Acad Sci U S A, 110 (2013) 1863-1868.

[21] H. Piotrowska-Kempisty, M. Ruciński, S. Borys, M. Kucińska, M. Kaczmarek, P. Zawierucha, M. Wierzchowski, D. Łażewski, M. Murias, J. Jodynis-Liebert, 3'-hydroxy-3,4,5,4'-tetramethoxystilbene, the metabolite of resveratrol analogue DMU-212, inhibits ovarian cancer cell growth in vitro and in a mice xenograft model, Scientific Reports, 6 (2016) 32627.

[22] A. Krämer, J. Green, J. Pollard, S. Tugendreich, Causal analysis approaches in ingenuity pathway analysis (ipa), Bioinformatics, 30 (2013) 523-530.

[23] V.K. Mootha, C.M. Lindgren, K.-F. Eriksson, A. Subramanian, S. Sihag, J. Lehar, P. Puigserver, E. Carlsson, M. Ridderstråle, E. Laurila, PGC-1 $\alpha$-responsive genes involved in oxidative phosphorylation are coordinately downregulated in human diabetes, Nature genetics, 34 (2003) 267-273.

[24] M. Wade, Y.-C. Li, G.M. Wahl, MDM2, MDMX and p53 in oncogenesis and cancer therapy, Nat. Rev. Cancer., 13 (2013) 83-96.

[25] H. Hong, K. Takahashi, T. Ichisaka, T. Aoi, O. Kanagawa, M. Nakagawa, K. Okita, S. Yamanaka, Suppression of Indued Pluripotent Stem Cell Generation by the p53-p21 Pathway, Nature, 460 (2009) 1132-1135.

[26] J. Syed, A. Chandran, G.N. Pandian, J. Taniguchi, S. Sato, K. Hashiya, G. Kashiwazaki, T. Bando, H. Sugiyama, A Synthetic Transcriptional Activator of Genes Associated with the Retina in Human Dermal Fibroblasts, Chembiochem, 16 (2015) 1497-1501.

[27] D. Hanahan, R.A. Weinberg, Hallmarks of cancer: the next generation, Cell, 144 (2011) 646-674.

[28] K.T. Bieging, S.S. Mello, L.D. Attardi, Unravelling mechanisms of p53-mediated tumour suppression, Nat. Rev. Cancer., 14 (2014) 359-370.

[29] R. Aloni-Grinstein, Y. Shetzer, T. Kaufman, V. Rotter, p53: The barrier to cancer stem cell formation, FEBS letters, 588 (2014) 2580-2589. 


\section{Antitumor Activity by Sequence-Specific HAT Inhibitors}

Zutao $\mathrm{Yu}^{\mathrm{a}}$, Junichi Taniguchi ${ }^{\mathrm{a}}$, Yulei Wei ${ }^{\mathrm{a}}$, Toshikazu Bando ${ }^{\mathrm{a}}$, Hiroshi Sugiyama ${ }^{\mathrm{a}, \mathrm{b}^{*}}$

${ }^{a}$ Department of Chemistry, Graduate School of Science, Kyoto University Kitashirakawa-Oiwakecho, Sakyo-ku, Kyoto 606-8502 (Japan)

b Premier International Research Center, Institute for Integrated Cell-Material Sciences (WPI-iCeMS), Kyoto University Yoshida-Ushinomiyacho, Sakyo-ku, Kyoto 606-8501 (Japan).

Table of Contents:

S2 Synthetic route of 2

S3 SW620 viability data

S4 GSEA gene set information

S5-S9 ESI-MS data of whole compounds 


\section{Synthetic route of 2}

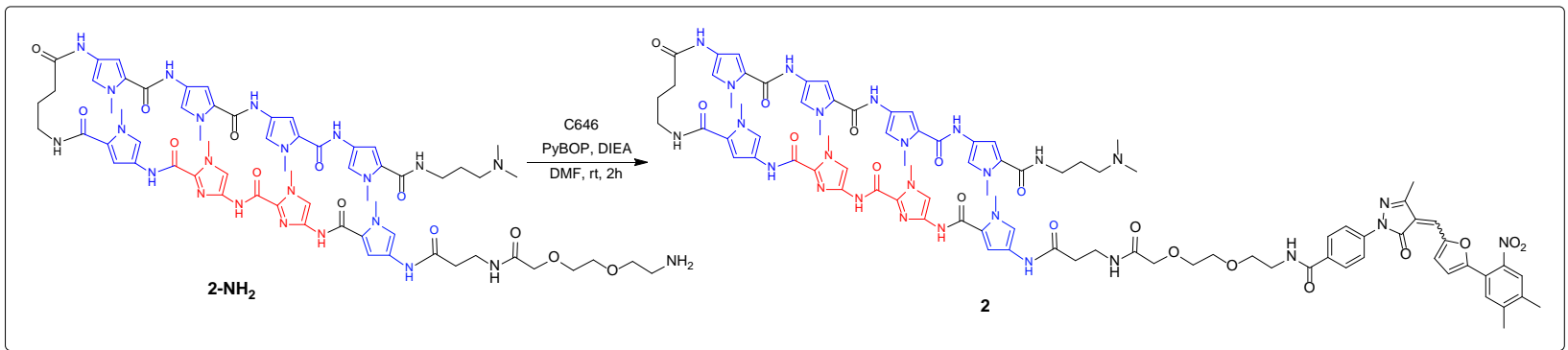

General conditions: C646, PyBOP, DIEA, DMF, rt, 2 h. 


\section{SW620 viability data}

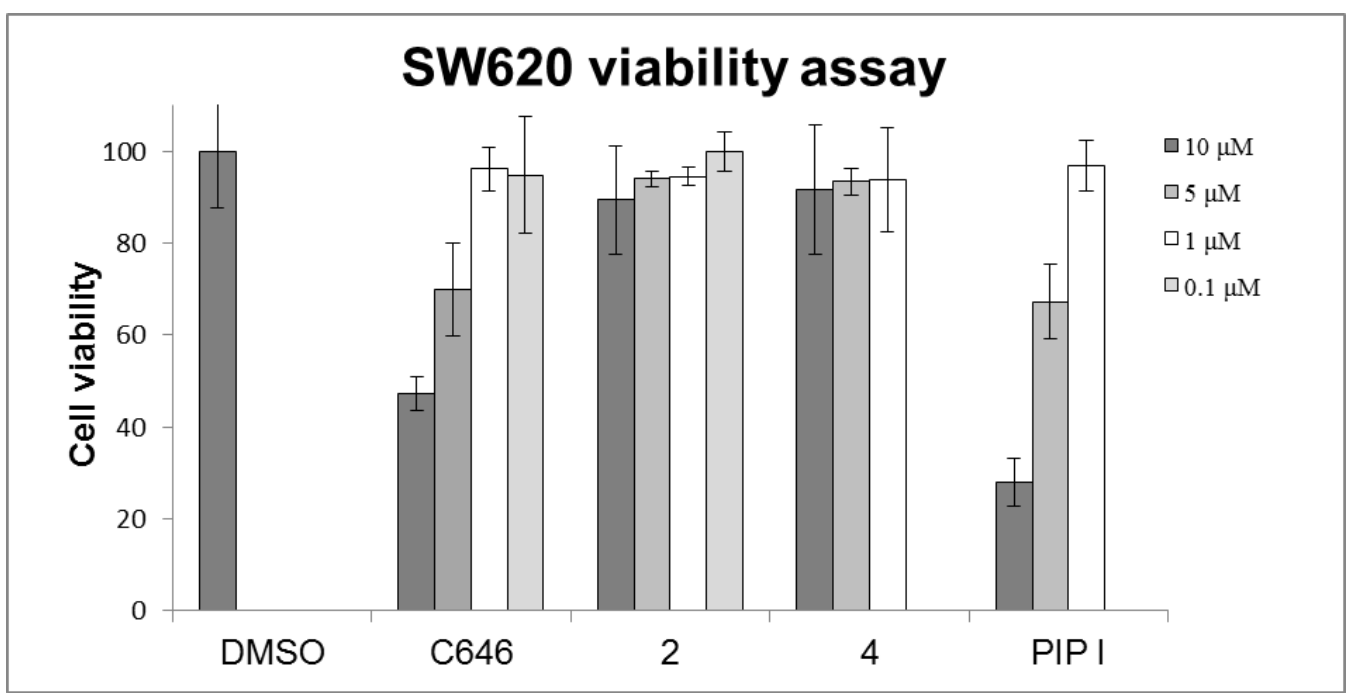

Cell viability assay in SW620 cell line by WST-8 method. Cells were grown in media for 24 hs. Then media was replenished with varying concentrations of conjugates 2 and 4 (0.1, 1,5 and $10 \mu \mathrm{M})$ for 96 hs. Cell viability of SW620 was measured by WST-8 method. Each bar represents mean \pm SD from 96 wells. ${ }^{*} p<0.05$. 


\section{GSEA gene set information}

Gene testing dataset was downloaded from Gene set enrichment analysis (GSEA) database, named KEGG gene sets, gene symbols (c2.cp.kegg.v5.2.symbols.gmt). It contains 186 pathways and thousands of genes. The following table shows p53 pathway genes.

CASP9,CASP8, SFN, TSC2, IGF1, CDK1, GADD45B, RCHY1, ZMAT3, IGFBP3, RRM2B, BAI1, TP73, SERPINB5RPRM, PPM1D, BID, MDM4, BAX, MDM2, TP53AIP1, CASP3, TP53I3, PMAIP1, PIDD RFWD2, PERP, GADD45G, EI24, SESN2, ATM, ATR, SESN3, CHEK2, APAF1, CDKN2A, RRM2, CDKN1A, BBC3, GADD45A, TNFRSF10B, DDB2, GTSE1, SIAH1, CCND1, CD82, PTEN, CDK2, CHEK1, SESN1, CDK4, SERPINE1, TP53, CCNE2 FAS, CDK6, CYCS, STEAP3, CCNB2, LOC651610, CCND2, SHISA5, CCNB1, CCNG1, CCNE1, CCNB3, THBS1, CCNG2, CCND3 


\section{ESI-MS data of whole compounds}

PIP-I was obtained as a white powder. MS (ESI-TOF): $\mathrm{m} / \mathrm{z}$ calcd for $\mathrm{C}_{57} \mathrm{H}_{71} \mathrm{~N}_{21} \mathrm{O}_{10}{ }^{2+}$ $[M+2 \mathrm{H}]^{2+}$ : 604.7841; found: 604.7302; HPLC: $t_{\mathrm{R}}=16.09 \mathrm{~min}(0.1 \% \mathrm{TFA} / \mathrm{MeCN}$, linear gradient 0-100\%, 0-40 min).

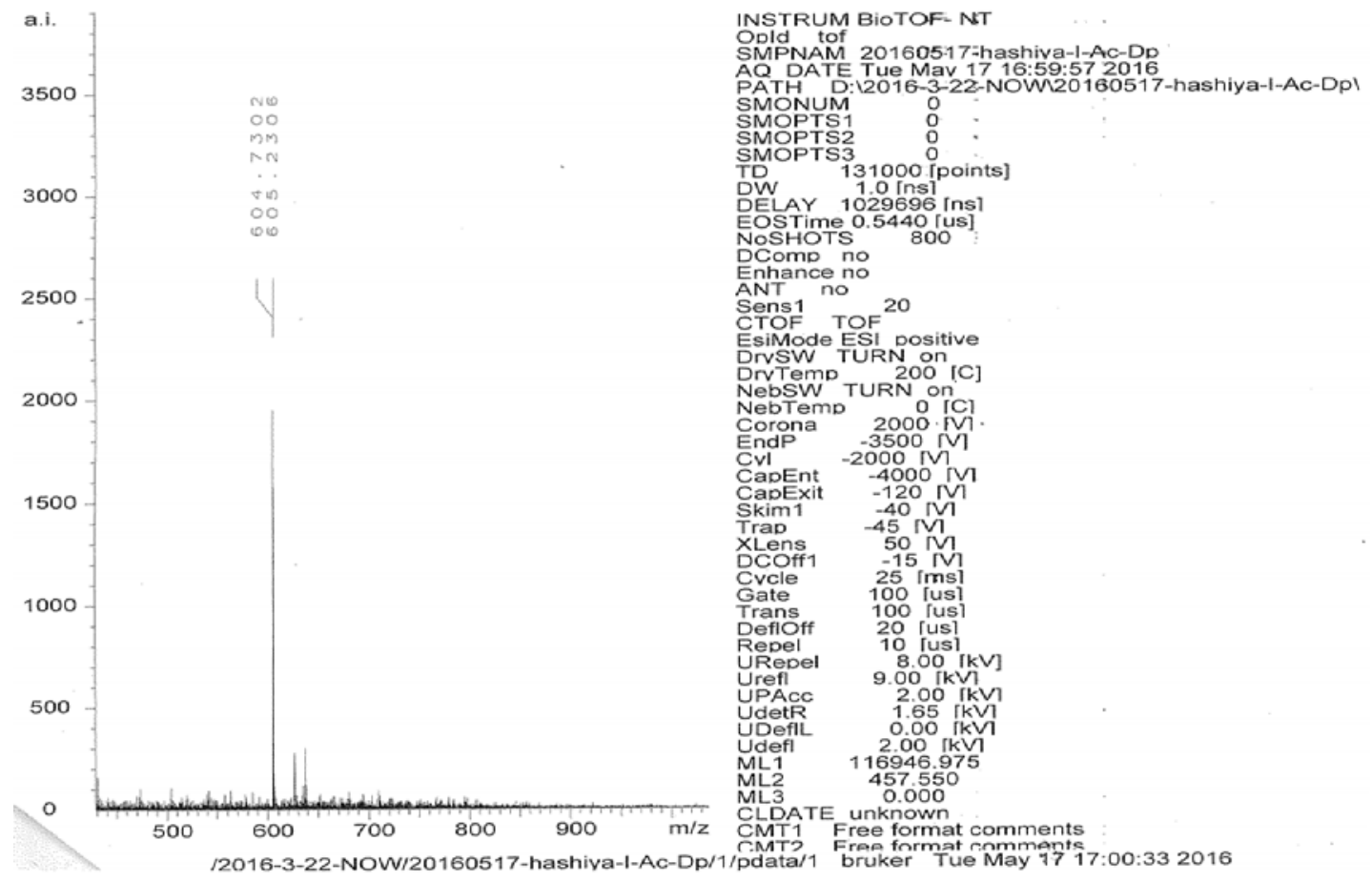

1-NH2 was obtained as a white powder. MS (ESI-TOF): $m / z$ calcd for $\mathrm{C}_{61} \mathrm{H}_{77} \mathrm{~N}_{23} \mathrm{O}_{11}{ }^{2+}$ $[M+2 \mathrm{H}]^{2+}:$ 654.8159; found: 654.6877; HPLC: $t_{\mathrm{R}}=10.06 \mathrm{~min}(0.1 \% \mathrm{TFA} / \mathrm{MeCN}$, linear gradient $0-100 \%, 0-20 \mathrm{~min}$ ).

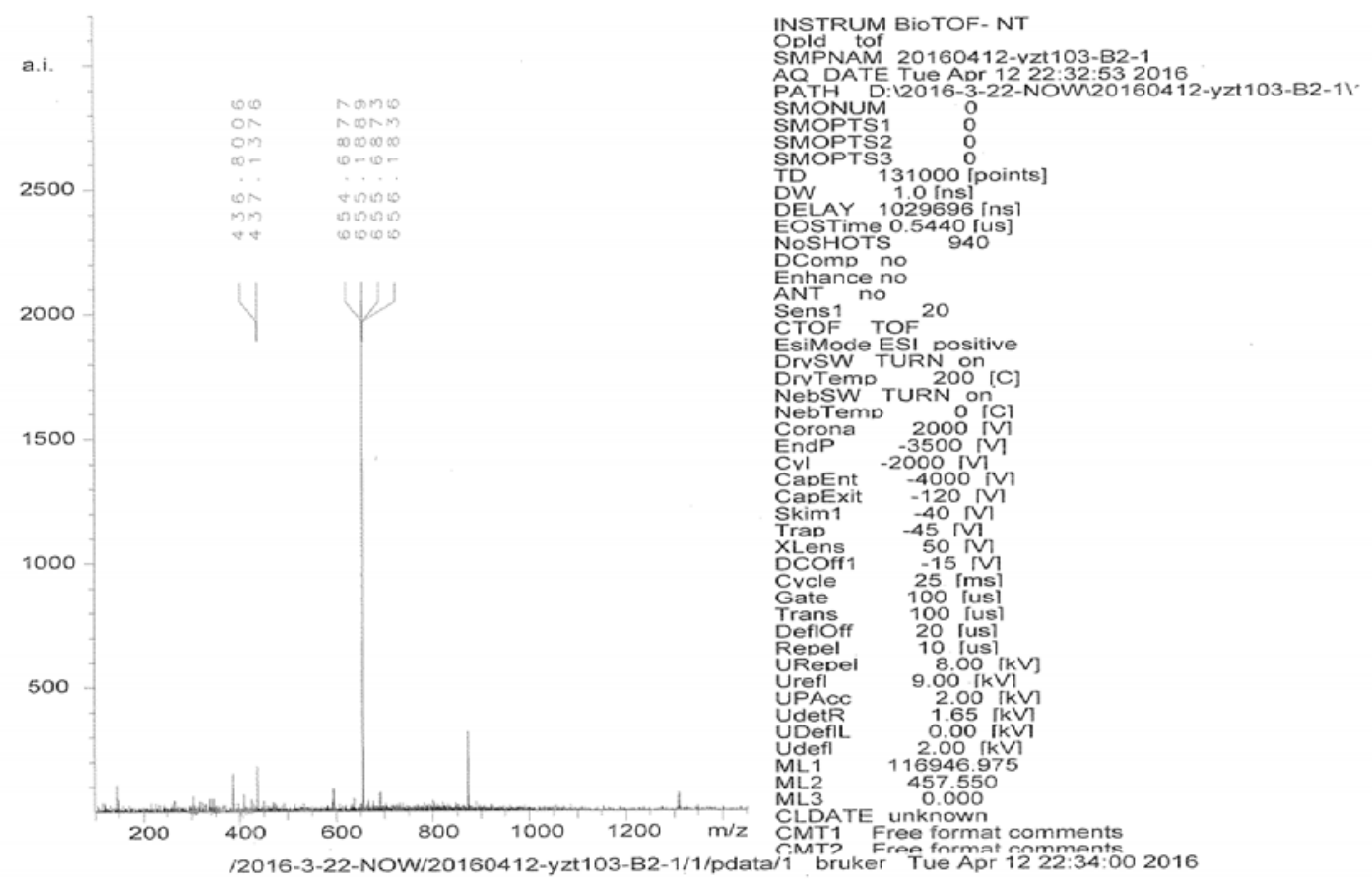


2-NH2 was obtained as a white powder. MS (ESI-TOF): $m / z$ calcd for $\mathrm{C}_{64} \mathrm{H}_{85} \mathrm{~N}_{23} \mathrm{O}_{13}{ }^{2+}$ $[M+2 \mathrm{H}]^{2+}$ : 691.8343; found: 691.6911; HPLC: $t_{\mathrm{R}}=10.11 \mathrm{~min}(0.1 \% \mathrm{TFA} / \mathrm{MeCN}$, linear gradient 0-100\%, 0-20 min).
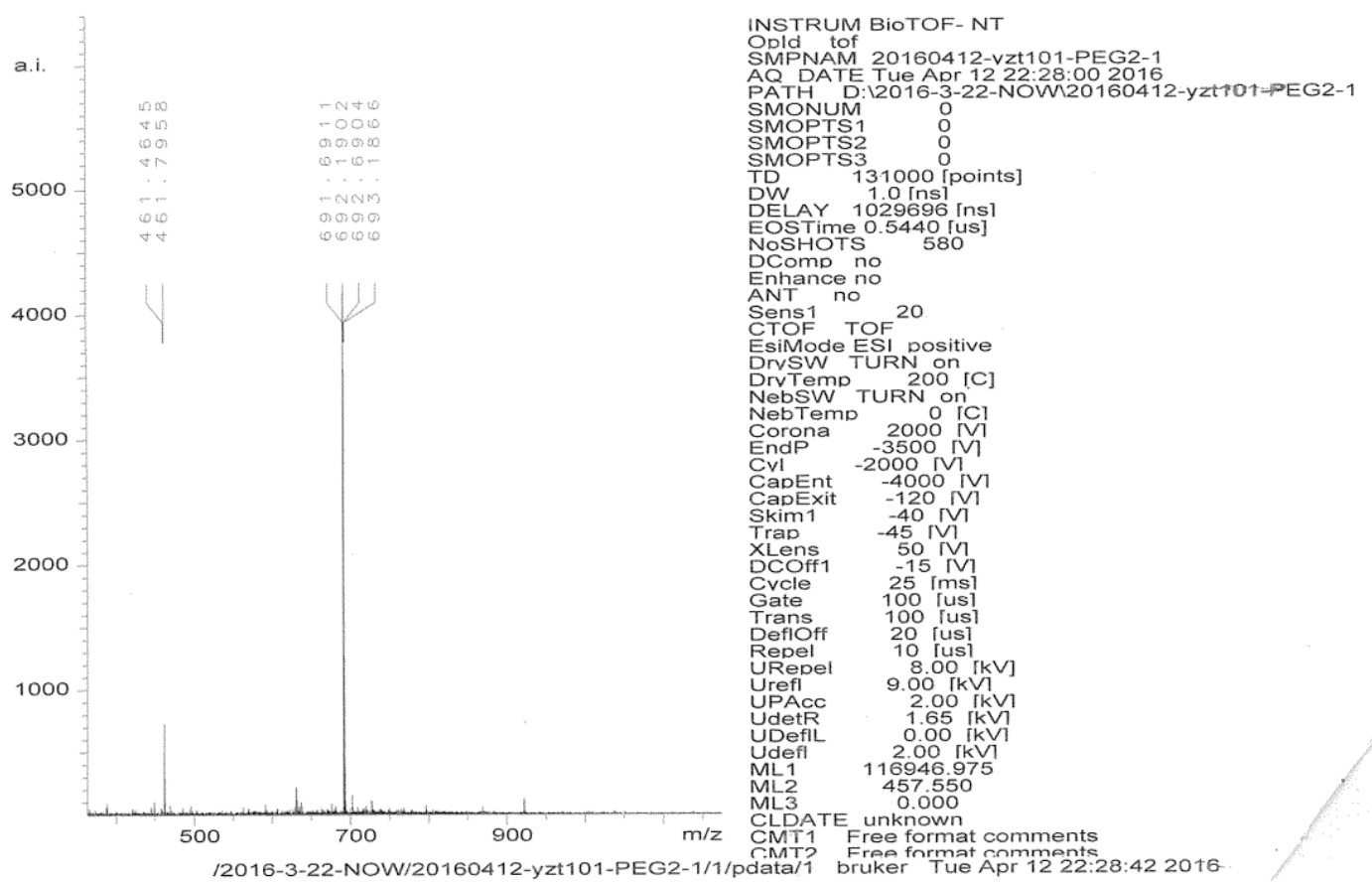

3-NH2 was obtained as a white powder. MS (ESI-TOF): $\mathrm{m} / \mathrm{z}$ calcd for $\mathrm{C}_{67} \mathrm{H}_{91} \mathrm{~N}_{23} \mathrm{O}_{15}{ }^{2+}$ $[M+2 \mathrm{H}]^{2+}:$ 728.8527; found: 728.7889; HPLC: $t_{\mathrm{R}}=10.18 \mathrm{~min}(0.1 \% \mathrm{TFA} / \mathrm{MeCN}$, linear gradient 0-100\%, 0-20 min).
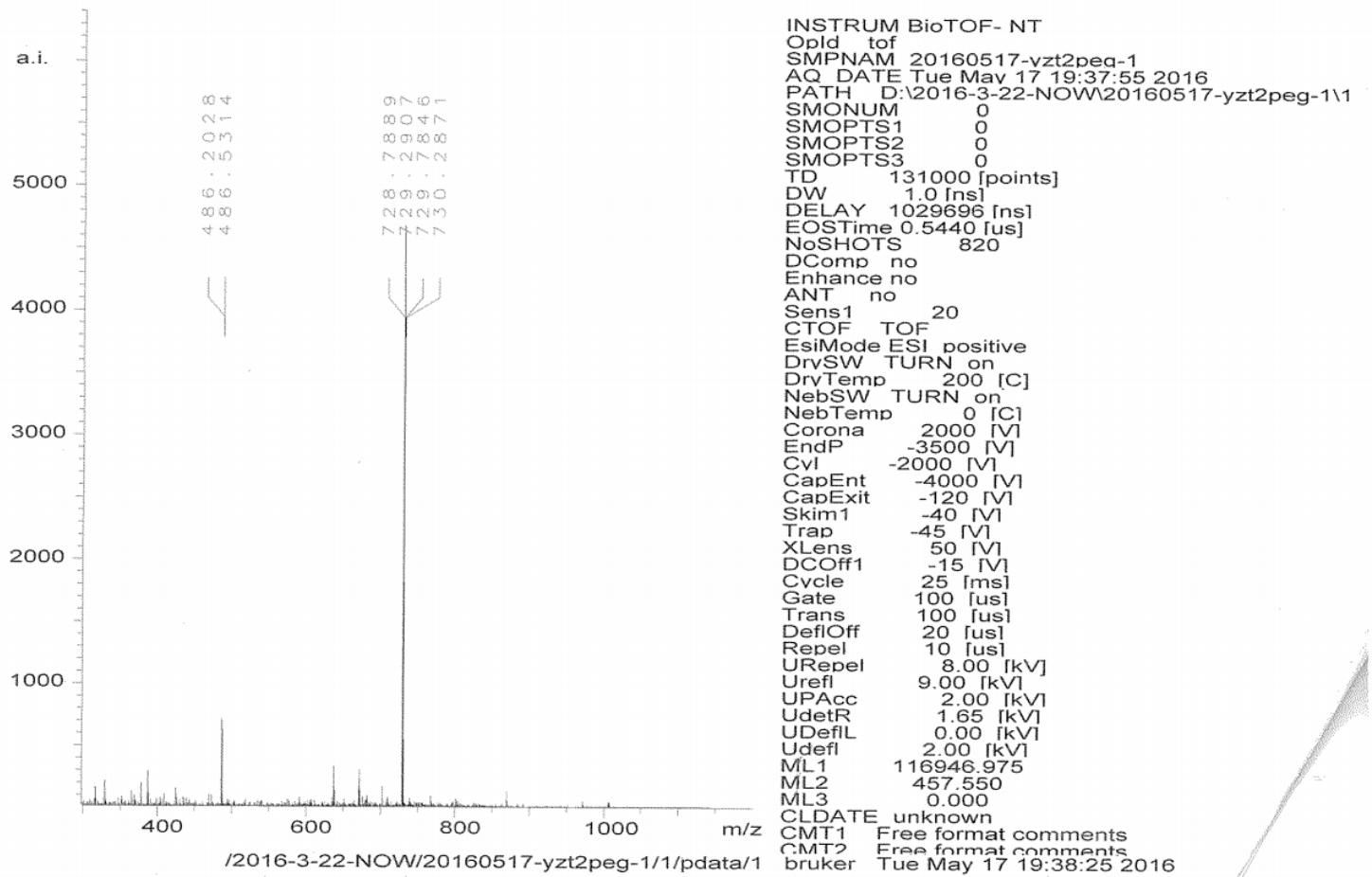
4-NH2 was obtained as a white powder. MS (ESI-TOF): $m / z$ calcd for $\mathrm{C}_{63} \mathrm{H}_{84} \mathrm{~N}_{24} \mathrm{O}_{13}{ }^{2+}$ $[M+2 \mathrm{H}]^{2+}$ : 692.3320; found: 692.3352; HPLC: $t_{\mathrm{R}}=9.692 \mathrm{~min}(0.1 \% \mathrm{TFA} / \mathrm{MeCN}$, linear gradient 0-100\%, 0-20 min).

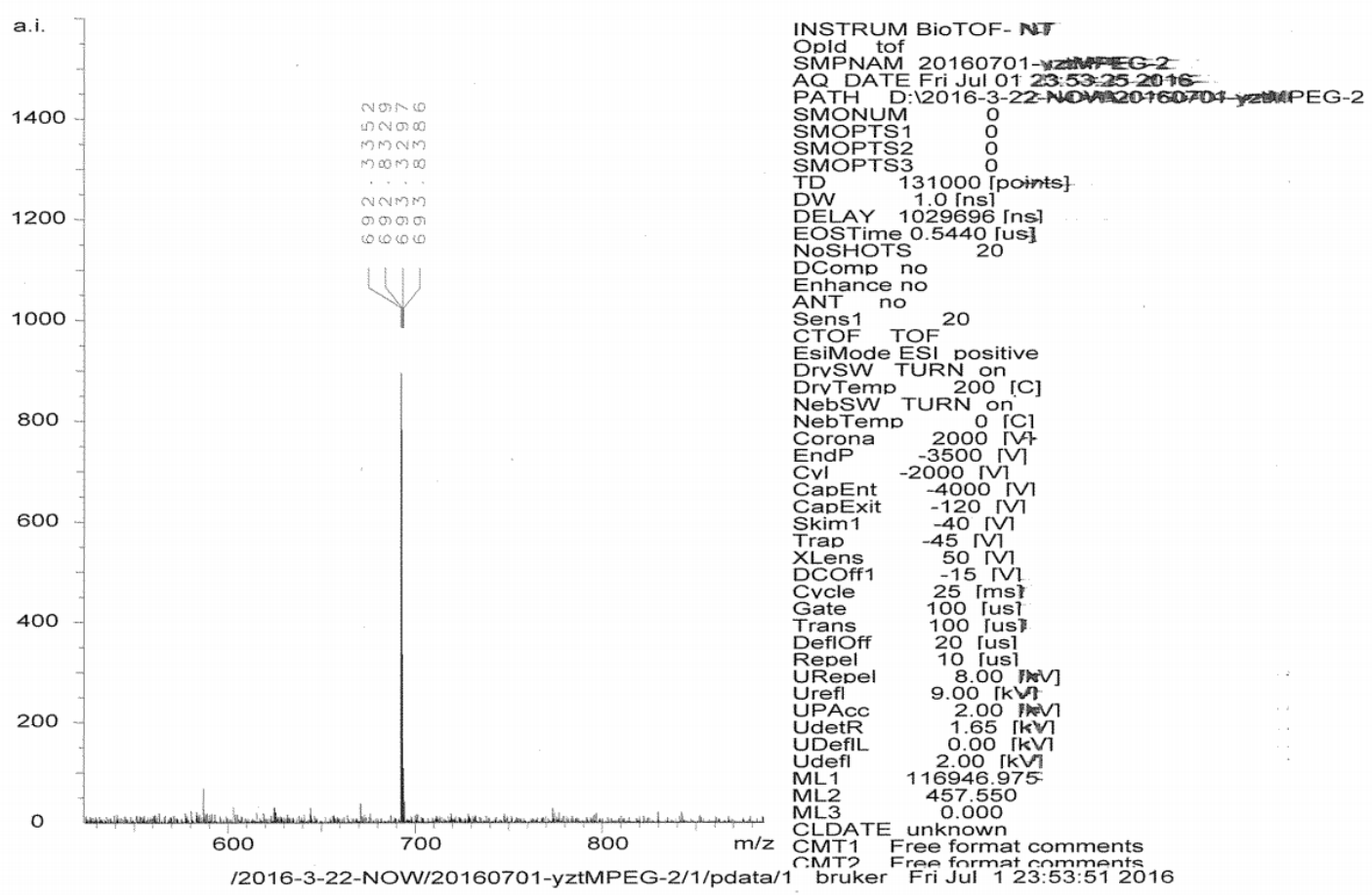

1 was obtained as a red powder. MS (ESI-TOF): $\mathrm{m} / \mathrm{z}$ calcd for $\mathrm{C}_{85} \mathrm{H}_{96} \mathrm{~N}_{26} \mathrm{O}_{16}{ }^{2+}$ $[M+2 \mathrm{H}]^{2+}$ : 868.3744; found: 868.2229; HPLC: $t_{\mathrm{R}}=14.05 \mathrm{~min}(0.1 \% \mathrm{TFA} / \mathrm{MeCN}$, linear gradient 0-100\%, 0-20 min).

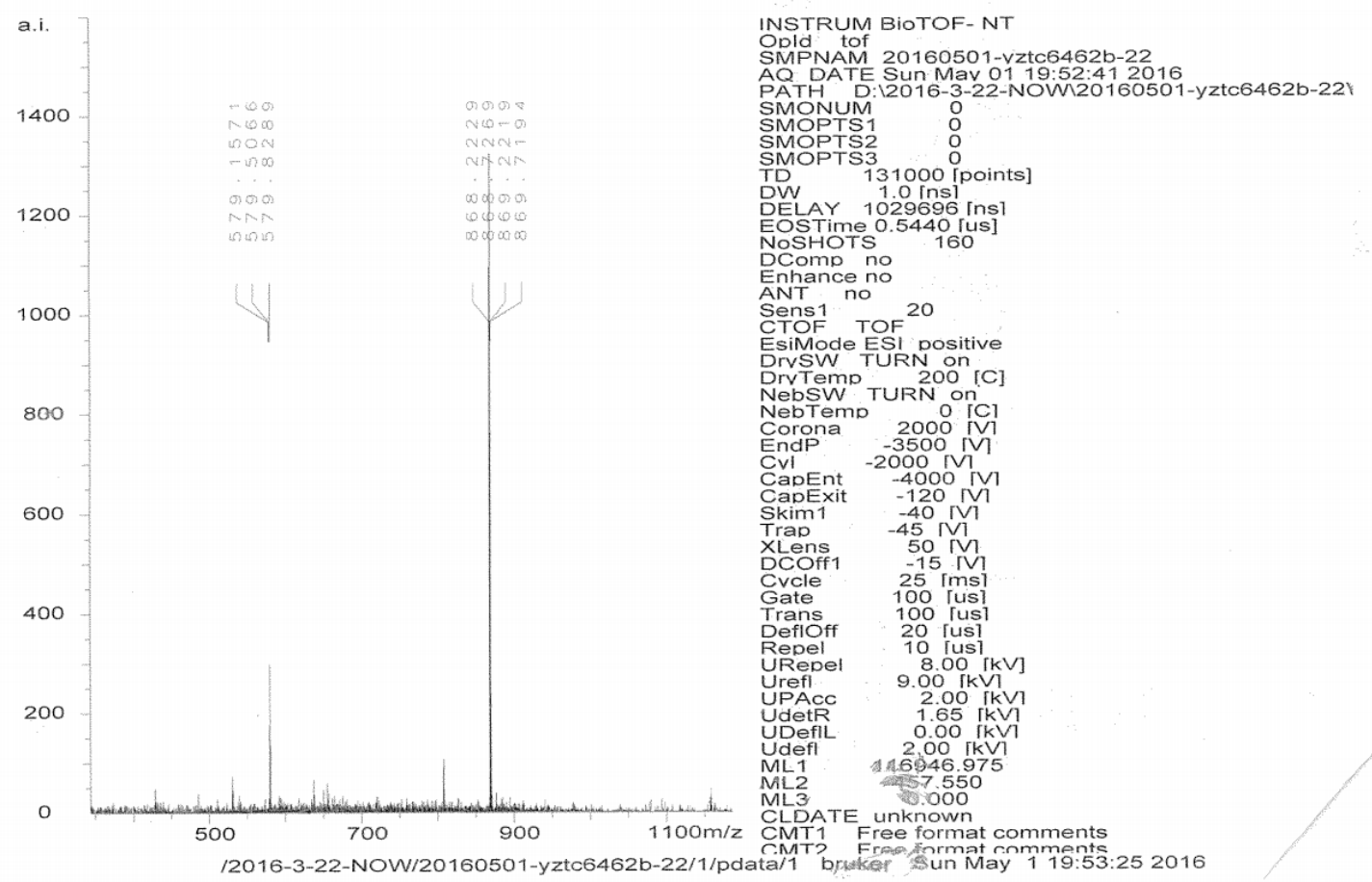


2 was obtained as a red powder. MS (ESI-TOF): $\mathrm{m} / \mathrm{z}$ calcd for $\mathrm{C}_{88} \mathrm{H}_{102} \mathrm{~N}_{26} \mathrm{O}_{18}{ }^{2+}$ $[M+2 \mathrm{H}]^{2+}$ : 905.3927; found: 905.3164; HPLC: $t_{\mathrm{R}}=14.10 \mathrm{~min}(0.1 \% \mathrm{TFA} / \mathrm{MeCN}$, linear gradient $0-100 \%, 0-20 \mathrm{~min})$.
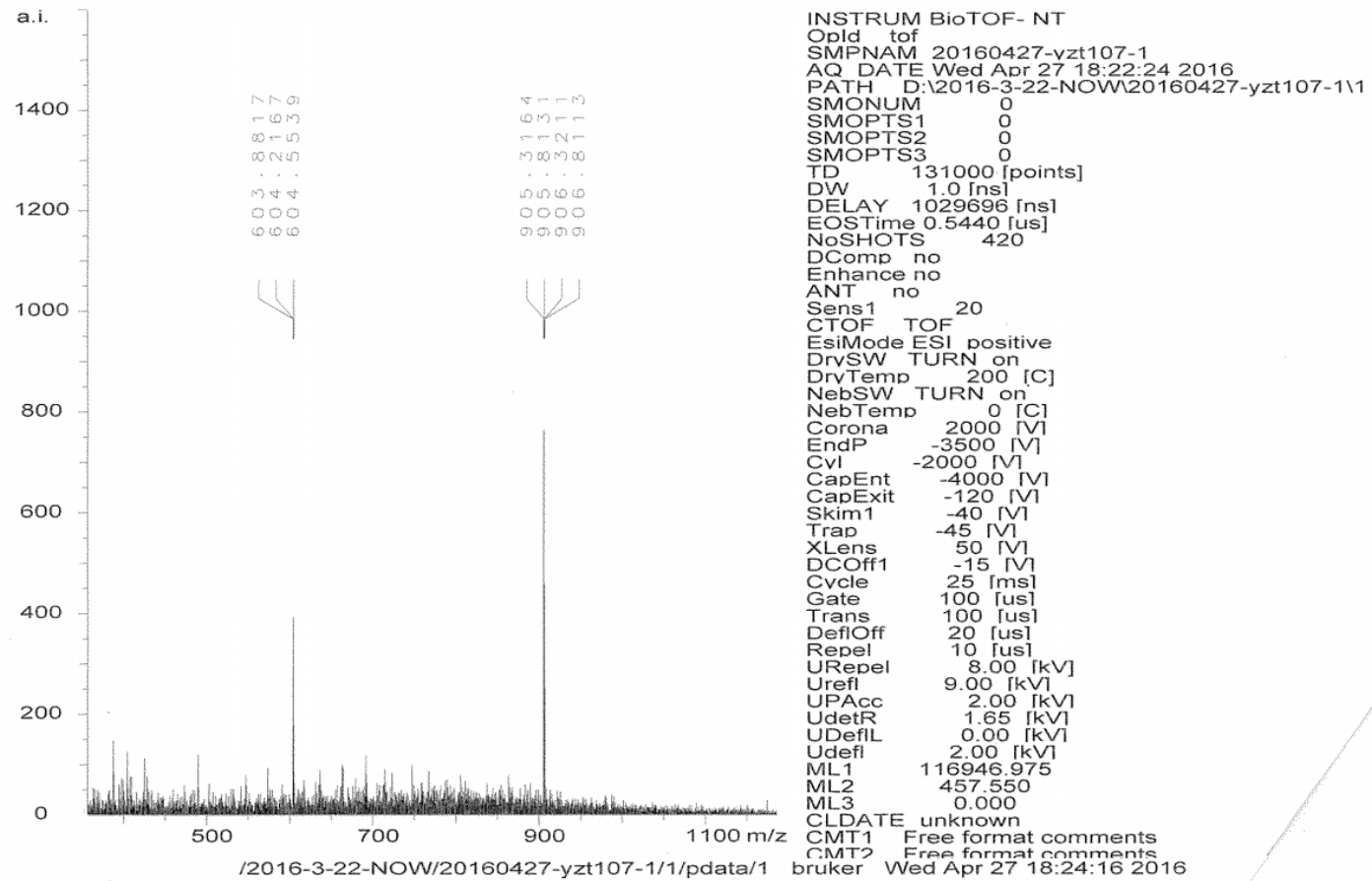

3 was obtained as a red powder. MS (ESI-TOF): $\mathrm{m} / \mathrm{z}$ calcd for $\mathrm{C}_{91} \mathrm{H}_{108} \mathrm{~N}_{26} \mathrm{O}_{20}{ }^{2+}$ $[M+2 \mathrm{H}]^{2+}$ : 942.4111; found: 942.4408; HPLC: $t_{\mathrm{R}}=14.19 \mathrm{~min}(0.1 \% \mathrm{TFA} / \mathrm{MeCN}$, linear gradient $0-100 \%, 0-20 \mathrm{~min})$.
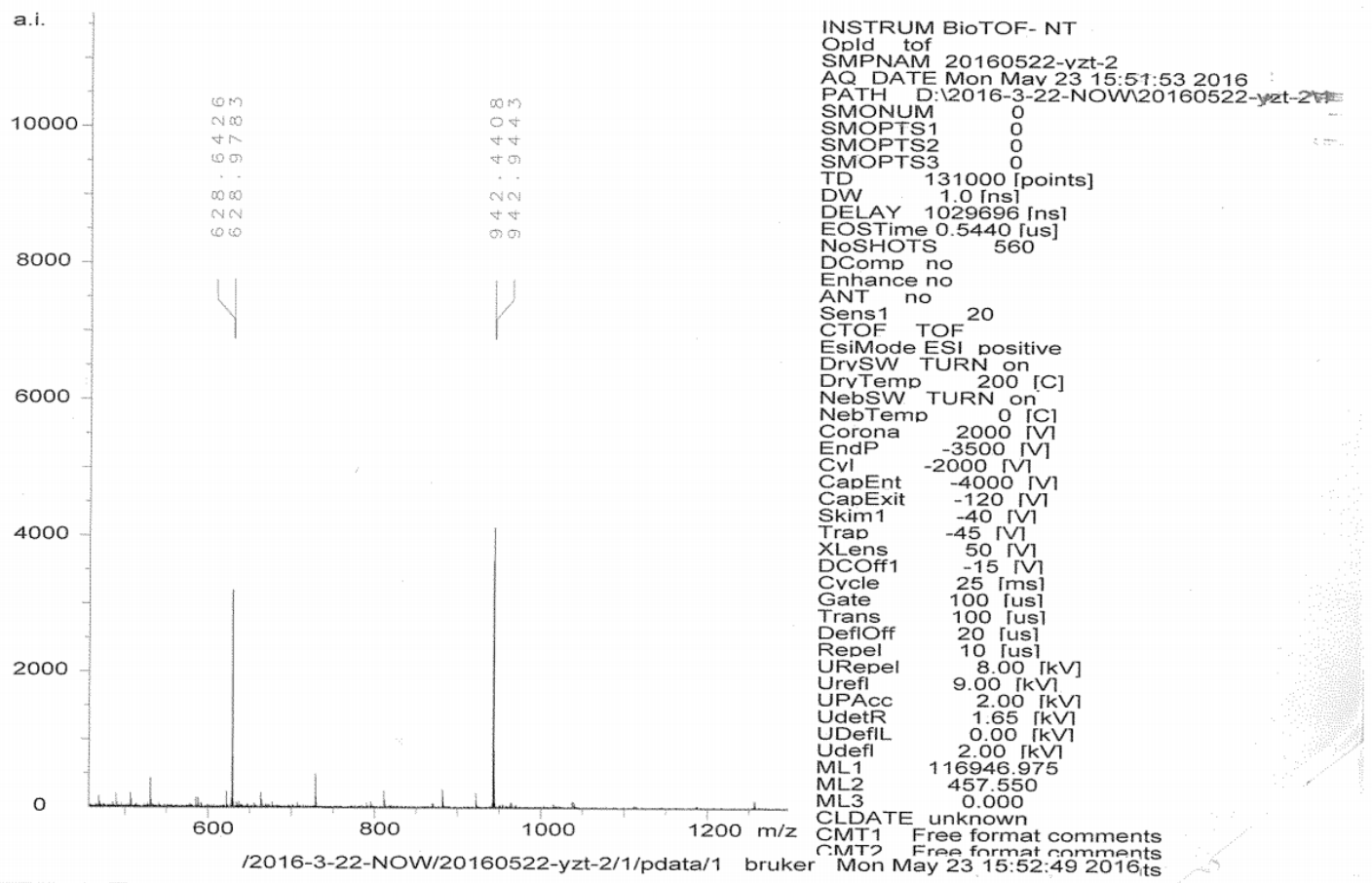
4 was obtained as a red powder. MS (ESI-TOF): $\mathrm{m} / \mathrm{z}$ calcd for $\mathrm{C}_{87} \mathrm{H}_{101} \mathrm{~N}_{27} \mathrm{O}_{18}{ }^{2+}$ $[M+2 \mathrm{H}]^{2+}$ : 905.8904; found: 906.8879; HPLC: $t_{\mathrm{R}}=13.83 \mathrm{~min}(0.1 \% \mathrm{TFA} / \mathrm{MeCN}$, linear gradient $0-100 \%, 0-20 \mathrm{~min})$.
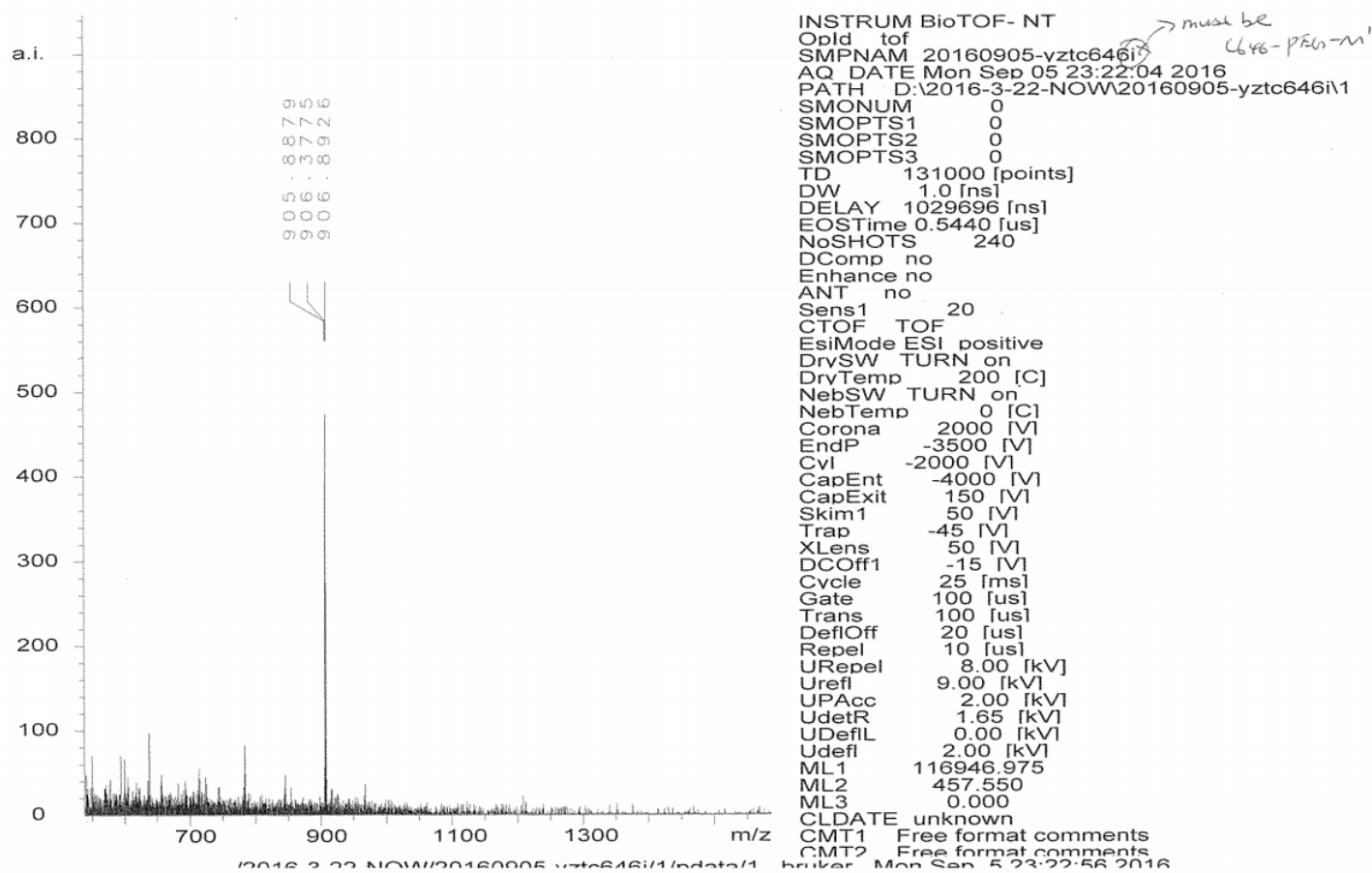